\title{
ARTIGOS
}

\section{Caracterização fisiológica, patogênica e análise isoenzimática de isolados monospóricos e multispóricos de Colletotrichum gloeosporioides.}

\author{
Ilka M árcia Ribeiro de Souza Serra ${ }^{1 *}$, Rildo Sartori Barbosa Coelho ${ }^{1}$, M aria M enezes
}

${ }^{1}$ U niversidade F ederal R ural de Pernambuco, UFRPE, Departamento de A gronomia / Fitossanidade, CEP 52171-900, D ois I rmãos, R ecife, PE, e-mail: ilka.tt@gmail.com

* Parte da Tese de Doutorado da primeira autora, Bolsista do CN Pq.

A utor(a) para correspondência: Ilka M árcia R .de S Serra

Data de chegada: 28/12/2005. A ceito para publicação em: 10/12/2007

1305

\section{RESUMO}

Serra, I.M .R.S.; Coelho, R.S.B .; M enezes, M . Caracterização fisiológica, patogênica e anál ise isoenzimática de isolados monospóricos e multispóricos de Colletotrichum gloeosporioides. Summa Phytopathologica, v.34, n.2, p.113-120, 2008

Foram caracterizados isolados monospóricos, obtidos de seis isolados multispóricos de Colletotrichum gloeosporioides, de cajueiro e mangueira, quanto à morfologia das colônias, crescimento micelial em BDA, patogenicidade e análise isoenzimática. As colônias dos isolados multispóricos apresentaram diversidade quanto à cor e aspecto, mas não foram observadas variações expressivas na morfologia dos 60 isolados monospóricos, quando comparados aos respectivos multispóricos, e apenas em dois isolados foi possível observar características morfológicas diferentes. Os isolados estudados exibiram bom crescimento em BDA, aos seis dias de incubação. A Iguns isolados monospóricos, obtidos de quatro multispóricos de cajueiro e mangueira, foram heterogêneos no crescimento micelial. A patogenicidade foi o parâmetro que melhor caracterizou a variação entre isolados monospóricos e multispóricos de C. gloeosporioides. Diferentes níveis de agressividade foram observados entre e dentro dos isolados monospóricos e multispóricos. Os padrões eletroforéticos de isoesterases demonstraram que não houve variação, quanto à análise isoenzimática, entre os isolados monospóricos e os multispóricos dos quais foram originados. Os resultados deste trabal ho sugerem que a escolha do tipo de isolado de C. gloeosporioides para estudos em cajueiro e mangueira deve ser precedida da comparação entre isolados monospóricos e multispóricos com base no crescimento micelial e patogenicidade.

Palavras-chaves adicionais: antracnose, monospóricos, mangueira, cajueiro.

\section{ABSTRACT}

Serra I.M .R.S.; Coelho R.S.B.; M enezes, M. Physiologic and pathogenic characterization, and isozyme analysis of monosporic and multisporic isolates of Colletotrichum gloeosporioides. Summa Phytopathologica, v.34, n.2, p.113-120, 2008

Monosporic isolates of Colletotrichum gloeosporioides obtained from six cashew and mango trees multisporic isolates were characterized for colony morphology, mycelial growth on BDA, pathogenicity and isozyme analysis. The colonies of multisporic isolates presented diversity of color and aspect, but expressive morphological variations were not observed in 60 monosporic isolates compared to their respective multisporic. Only in two isolates it was possible to observe different morphologic characteristics. All the studied isolates showed good growth on BDA until six days after incubation. Some monosporic isolates obtained from four cashew and mango multisporic ones showed heterogeneous mycelial growth. Pathogenicity was the variable that best characterized the variation between monosporic and multisporic isolates of $C$. gloeosporioides. Different aggressiveness levels were observed among and within monosporic and multisporic isolates. In the analysis of isozymes, the electrophoretical patterns of isoesterases showed no variation among the monosporic isolates and the parental multisporic ones. The results of this work suggest that the selection of the $C$. gloeosporioides type isolate for studies on cashew and mango should be preceded by a comparison between monosporic and multisporic isolates based upon mycelial growth and pathogenicity.

Additional keywords: anthracnose, monosporic, mango tree, cashew tree.

0 gênero Colletotrichum é um dos mais importantes entre os fungos fitopatogênicos a nível mundial, especialmente nas regiões tropicais e subtropicais, envolvendo espécies que causam doenças de expressão econômica em leguminosas, cereais, hortaliças e culturas perenes, incluindo diversas frutíferas $(12,16)$.

A antracnose em frutíferas, causada na maioria dos casos por 
Colletotrichum gloeosporioides (Penz.) Penz. \& Sacc., é considerada uma doença economicamente importante no N ordeste do B rasil (30), incidindo sobre ramos novos, folhas, inflorescências e frutos. $\mathrm{N}$ as fol has, há o aparecimento de manchas escuras e de contornos irregulares, que resultam em lesões ou perfurações quando os tecidos necrosados se destacam. A s inflorescências afetadas apresentam flores escuras, tomando 0 aspecto de queimadas pelo fogo, morrendo a seguir. As lesões na ráquis podem levar à queda dos frutos, antes da maturação fisiológica, ou mumificação quando ainda novos. No período de maturação, há o aparecimento de lesões escuras e deprimidas na superfície do fruto, que podem atingir também a polpa $(24,28)$. A doença pode ocasionar prejuízos que variam em função do grau de susceti bilidade da planta hospedeira e das condições ambientais.

Espécies de Colletotrichum têm sido identificadas quase exclusivamente através da caracterização morfológica, cultural e molecular. Características como morfologia de conídios, presença ou ausência de setas, formação de apressórios, presença ou ausência de teleomorfo, coloração da colônia e taxa de crescimento micelial, são as mais utilizadas. M odernamente, características genéticas, usando marcadores moleculares, como análise de polimorfismo de comprimento de fragmento de restrição de DNA (RFLP), análise de polimorfismo de DNA amplificado ao acaso (RAPD) e análises isoenzimáticas têm sido amplamente usadas na caracterização e identificação de espécies do gênero Colletotrichum (11, 15, 32, 35).

A I guns autores afirmam que $C$. gloeosporioides apresenta grande variação morfológica efisiológica. A té mesmo isolados monoconidiais têm mostrado uma el evada variabilidade quando expostos a diferentes condições culturais $(8,18,23)$. I números trabal hos têm sido realizados utilizando-se isolados monospóricos de C. gloeosporioides, porém, não foram encontrados na literatura disponível estudos que demonstrem diferenças, sejam elas morfológicas, fisiológicas, genéticas e patogênicas, entre isolados monospóricos e multispóricos de $C$. gloeosporioides. Mesmo em relação a outros fungos, são raros os trabalhos abordando este aspecto. Pio-Ribeiro \& Chaves (27), analisando culturas monospóricas obtidas de 64 isolados de Colletotrichum lindemuthianum (Sacc. Et M agn.) Scrib., verificaram que a nível de raças, caracterizadas com base na reação de quatro diferenciadoras de feijoei ro comum (P haseol us vul garis $L$ ), não ocorreu variação entre isolados monospóricos e multispóricos. Nesse mesmo patossistema, O liveira et al. (26) também não observaram variação de raças em isolados monospóricos obtidos em 90 amostras de feijoeiro com sintomas da antracnose. No fungo entomopatogênico Lecanicillium lecanii (Zimm.) Zare \& Gams, Madrigal et al. (22) compararam sete isolados multispóricos e 28 monospóricos (quatro de cada multispórico), observando que em relação à morfologia (cor, aspecto da colônia e tipo do micélio) não houve diferenciação entre isolados monospóricos e multispóricos. No entanto, diferenças significativas ocorreram quanto à taxa de germinação dos conídios e esporulação.

O presente trabal ho objetivou caracterizar isolados monospóricos e multispóricos de C. gloeosporioides, obtidos de cajueiro (Anacardium occidentale L.) e mangueira (Mangifera indica L.), cultivados em diferentes estados do Nordeste, quanto aos aspectos culturais das colônias, características fisiológicas, patogênicas e análise isoenzimática.

\section{MATERIALE MÉTODOS}

Obtenção dos isolados originais

Os isolados multispóricos foram obtidos de cajueiro e mangueira, dos estados do M aranhão, Pernambuco e Paraíba, e codificados com base na procedência, em CMA (cajueiro-MA), CPE (cajueiro-PE), $C P B$ (cajueiro- $P B$ ), M M A (mangueira- $M A$ ), M PE (mangueira- $P E$ ), e $M P B$ (mangueira-PB). 0 fungo foi isolado a partir de folhas com sintomas de antracnose. Fragmentos de tecidos foram retirados das margens das lesões, desinfestados superficialmente em uma solução de hipocl orito de sódio a 1\%, durante 2 minutose, em seguida, lavados, em duas porções consecutivas, de água destilada e esterilizada. Logo após, os fragmentos foram plaqueados em meio de cultura batatadextrose-ágar (BDA ) e, incubados à $25 \pm 2^{\circ} \mathrm{C}$, com fotoperíodo de 12 horas. A partir das culturas puras de C. gloeosporioides foram preparadas as monospóricas.

A spectos culturais das colônias de isolados monospóricos e multispóricos de Colletotrichum gloeosporioides

Dez culturas monospóricas foram obtidas de cada um dos seis isolados originais, perfazendo o total de 60 isolados, através do seguinte procedimento: preparou-se uma suspensão de conídios, das culturas de C. gloeosporioides com cinco dias de idade, e após leve agitação dos tubos que continham a suspensão, foi retirada uma alíquota de $1 \mathrm{ml}$ e colocada na superfície do meio BDA, contido numa placa de Petri, e em seguida espalhou-se cuidadosamente sobre o meio a suspensão de conídios. A s placas foram incubadas durante 24 horas a temperatura de $25 \pm 2{ }^{\circ} \mathrm{C}$, sob fotoperíodo de 12 horas. A pós o período de incubação, e com auxílio de um microscópio estereoscópico, foram visualizados os conídios germinados, e estes transferidos individual mente para o centro de placa de Petri, contendo BDA. Cada cultura monospórica foi designada com um código referente ao isolado multispórico que lhe deu origem, procedendo-se à incubação durante sete dias, sob as mesmas condições de temperatura e luminosidade.

A avaliação dos isolados foi efetuada de forma comparativa entre as monospóricas e, também, em relação aos multispóricos de origem, e consistiu na observação do aspecto topográfico das colônias e coloração das mesmas.

Caracterização fisiológica e patogênica de Colletotrichum gloeosporioides

Crescimento micelial em BDA

Para o estudo das características fisiológicas, foram utilizados os 60 isolados monospóricos obtidos conforme descrito anteriormente. As placas foram incubadas a $25 \pm 2{ }^{\circ} \mathrm{C}$, sob fotoperíodo de 12 horas. Neste experimento, foi observado 0 crescimento do micélio, medindo-se diariamente o diâmetro da colônia em intervalos de 24 horas, com auxilio de uma régua milimetrada, etomando-se duas medições, em sentidos diametral mente opostos. Em seguida, foi estabelecida uma média de crescimento micelial em cada placa. A s leituras foram iniciadas 48 horas após a instalação do experimento, até a ocasião em que um dos isolados houvesse colonizado toda a superfície do meio de cultura, que correspondeu a seis dias de incubação para al guns isolados.

Patogenicidade dos isolados monospóricos e multispóricos

No estudo da patogenicidade foram utilizados 30 isolados monospóricos, sendo cinco de cada isolado multispórico (CM A, CPE, CPB, M M A, M PE, e M PB) escolhidos aleatoriamente.

$\mathrm{Na}$ avaliação do comportamento patogênico, os isolados foram inoculados em folhas destacadas de mangueira e cajueiro, usando-se discos de micélio e meio de cultura ( $5 \mathrm{~mm}$ de diâmetro) retirados de colônias jovens do patógeno, em BDA. A inoculação foi realizada utilizando o método com ferimento, produzido com estilete flambado, 
e depositando-se o inóculo em três pontos da superfície foliar. A pós a inoculação, as fol has foram acondicionadas em bandejas plásticas forradas com papel de filtro e mantidas em câmara úmida até o aparecimento dos sintomas. Para as testemunhas repetiram-se os mesmos procedimentos, porém sendo depositados somente discos de meio de cultura BDA. A s bandejas foram incubadas a $25 \pm 2^{\circ} \mathrm{C}$, sob fotoperíodo de 12 horas.

0 delineamento experimental utilizado foi 0 inteiramente casual izado com quatro repetições (representadas por bandejas), e cada parcela constituída por cinco folhas/bandeja, sendo os dados obtidos submetidos à anál ise de variância e as médias comparadas pelo teste de Tukey, ao nível de $5 \%$ de probabilidade.

A avaliação foi realizada aos sete dias após a inoculação, através da leitura do comprimento e largura das lesões e observação das características das lesões.

\section{Caracterização I soenzimática}

\section{Cultivo do fungo e obtenção do extrato protéico}

Foram utilizados 30 isolados monospóricos obtidos a partir de seis isolados multispóricos de C. gloeosporioides. Todos os isolados foram cultivados em $125 \mathrm{~mL}$ do meio BD (200g batata, $20 \mathrm{~g}$ dextrose/ litro de água destilada) durante seis dias, a temperatura de $25 \pm 2{ }^{\circ} \mathrm{C}$, sob fotoperíodo de 12 horas, com suave agitação duas vezes ao dia.

A coleta do micélio de cada isolado foi feita por filtração, após duas lavagens sucessivas com água destilada esterilizada gelada. Em seguida, $400 \mathrm{mg}$ de micélio foram trituradas em almofariz refrigerado com adição de $150 \mathrm{mg}$ de sacarose, $150 \mathrm{mg}$ de polivinilpirrolidona e $1 \mathrm{~mL}$ do tampão Tris-glicina 0,125 M, pH 8,2 . A pós o período de repouso de 12 horas, todas as amostras foram centrifugadas a $14.000 \mathrm{rpm}$, por 6 minutos. Os extratos protéicos foram estocados no congelador, para uso posterior.

\section{Preparo das placas de gel e corrida el etroforética}

Placas de gel de poliacrilamida a $5 \%$ em tampão tris-glicina a $0,125 \mathrm{M}, \mathrm{pH}$ 8,2, foram preparadas seguindo a metodologia descrita por A Ifenas et al. (2). A pós a polimerização completa do gel, este foi colocado numa cuba horizontal contendo 0 tampão Tris-glicina a $0,125 \mathrm{M}$, pH 8,2. Foram aplicados $10 \mathrm{~mL}$ do extrato protéico de cada isolado, individualmente, nas cavidades do gel. Como marcador foi utilizado o azul de bromofenol. A corrida eletroforética foi realizada a $4^{\circ} \mathrm{C}$, sob corrente constante de $10 \mathrm{~mA}$, sendo interrompida quando 0 corante marcador percorreu $6,5 \mathrm{~cm}$ do gel (4).

\section{Coloração para detecção de isoesterases}

Para revelação das bandas de esterase, o gel foi imerso por uma hora numa solução contendo $0,1 \mathrm{M}$ de tampão fosfato $\mathrm{pH}$ $6,5(100 \mathrm{~mL}), 1 \%$ a-naftil acetato $(50 \mathrm{mg})$ e $50 \mathrm{mg}$ de fast blue $R R$, e mantido no escuro, a temperatura de $37^{\circ} \mathrm{C}$. Em seguida, 0 gel foi imerso em ácido acético glacial $7 \%$ para a fixação das bandas (4).

Para avaliação dos perfis isoesterási cos dos isolados foram considerados os seguintes parâmetros: números de bandas, intensidade da cor e mobilidade relativa (Rf) no gel de poliacrilamida, a qual foi determinada pela fórmula: $R f=(d / D)$ $x 100$, onde $d=$ distância percorrida pela molécula; $D=$ distância percorrida pelo corante marcador (2). A avaliação da similaridade genética entre os isolados no sistema estudado, foi determinada usando o coeficiente de J accard, sendo a análise da matriz e o agrupamento genético realizado pelo método A ritmético $\mathrm{N}$ ão Ponderado de Determinação de Grupos (UPGMA) utilizando o programa NTSYS-pc.

\section{RESULTADOS E DISCUSSÃO}

A spectos culturais das colônias de isolados monospóricos e multispóricos de Colletotrichum gloeosporioides

A s colônias apresentaram grande diversidade com relação à cor e aspecto, de acordo com os diferentes isolados multispóricos. Porém quando comparados os isolados monospóricos com os originais (isolados multispóricos) não foi observada variação expressiva na morfologia da colônia, conforme mostra a Figura 1. A penas dois isolados monospóricos CM A e M PB, exibiram características morfológicas diferentes dos multispóricos de origem, o que sugere diversidade genética em um mesmo isolado multispórico. Em alguns isolados multispóricos como M M A, CPE e CPB foi visível a produção de massas de conídios na superfície da colônia, de coloração alaranjada. Somente os isolados monospóricos obtidos a partir de MPE, CPB e CPE apresentaram colônias de coloração alaranjada, com abundante produção de massa de conídios. A s colônias dos isolados multispóricos MPE, MPB e CMA variaram quanto à formação de micélio aéreo flocoso sem conídios aparentes, a micélio escasso e submerso, porém bem

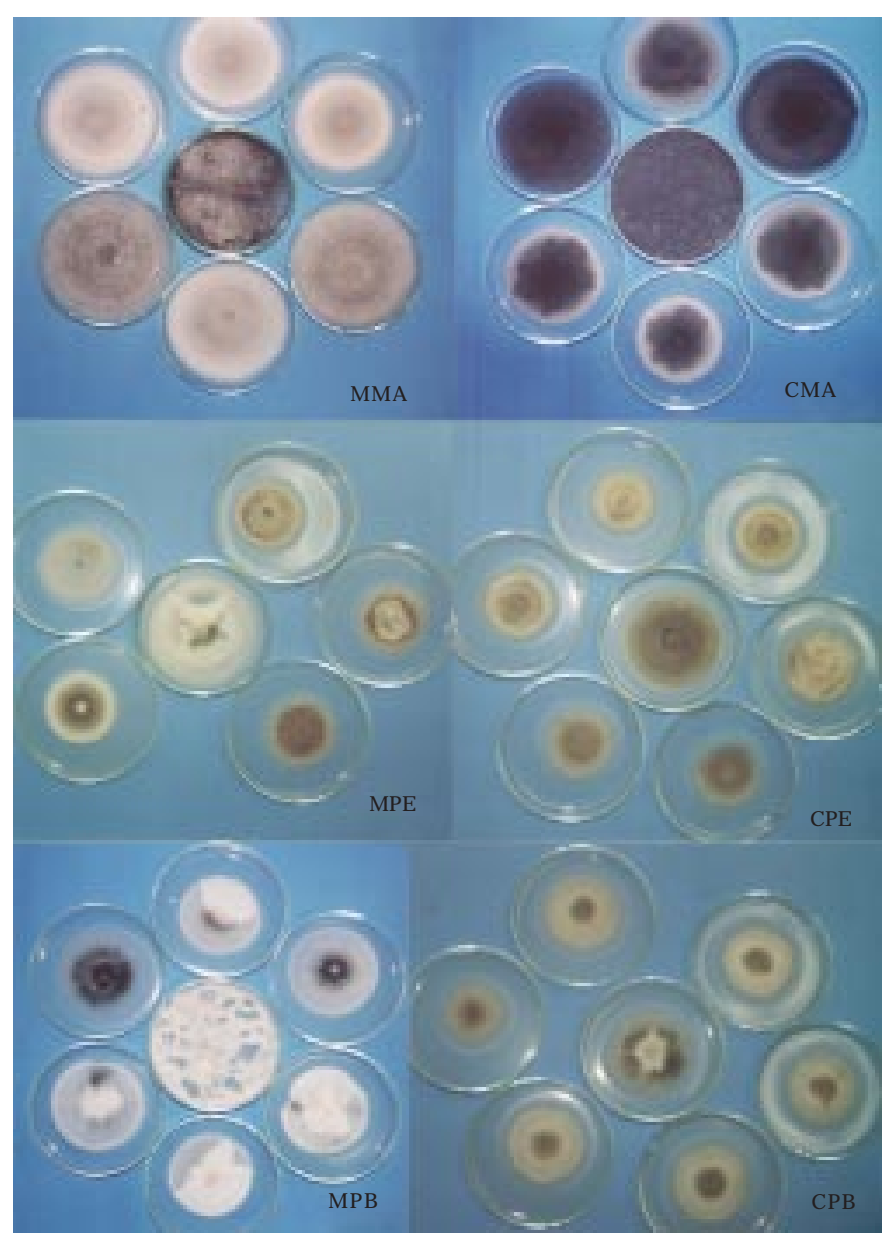

Figural. A specto cultural das colônias de isolados monospóricos e multispóricos (centro) 

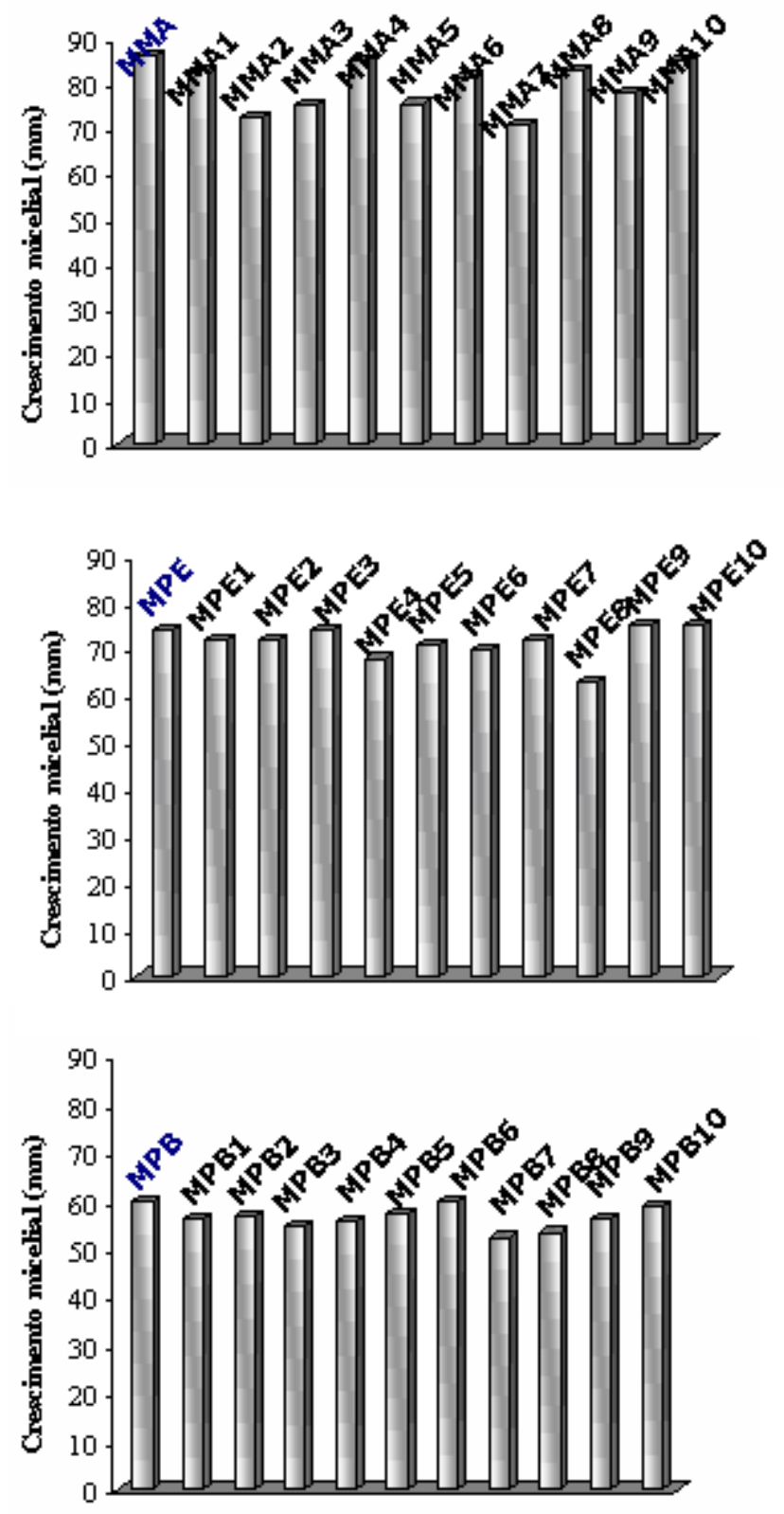
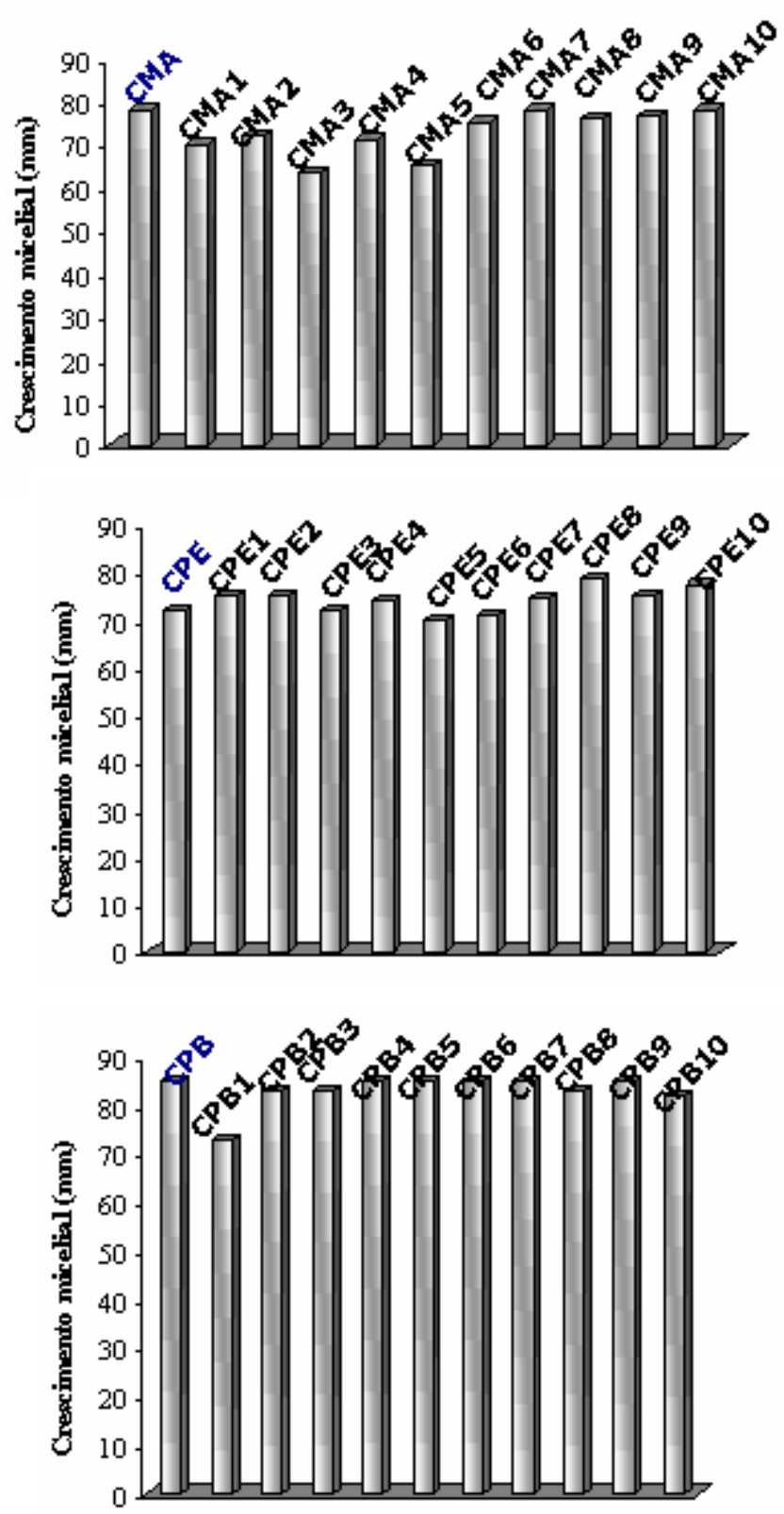

Figura 2. Crescimento micelial de isolados monospóricos e multispóricos de Colletotrichum gloeosporioides em meio BDA, aos seis dias de incubação.

esporulado (Figura 1). Segundo Menezes (23), isolados pertencentes à mesma espécie de C. gloeosporioides apresentaram entre si grande variabilidade no mesmo substrato, admitindo estar este fato relacionado com a presença de raças fisiológicas.

Os resultados obtidos mostram correlação com aqueles apresentados por alguns pesquisadores que avaliaram 0 comportamento de Colletotrichum spp. com base nas características culturais, como aspectos de colônias $(1,6,19,20)$. Ferraz (8) classificou isolados de espécies de Colletotrichum em grupos e subgrupos, em função da variação observada em cultura. Estudos baseados na caracterização cultural, como coloração e aspecto da colônia, realizados por J ohnston \& J ones, (19) puderam reconhecer 16 grupos distintos, de diversos isolados de Colletotrichum, obtidos de fruteiras na N ova Zelândia.
Caracterização fisiológica e patogênica de Colletotrichum gloeosporioides

Crescimento micelial em BDA

Os resultados obtidos para crescimento micelial dos diferentes isolados de C. gloeosporioides estão representados na Figura 2. Considerando que as culturas monospóricas foram obtidas a partir de um único conídio da colônia multispórica, não foram feitas repetições no experimento. 0 s isolados estudados apresentaram bom crescimento micelial em BDA, aos seis dias de incubação. Os isolados monospóricos oriundos dos multispóricos CPE e M PB não exibiram diferenças expressivas no crescimento micelial em BDA, aos seis dias de incubação. No entanto, al guns monospóricos obtidos de CM A, CPB, M M A e MPE foram heterogêneos no crescimento, destacando-se o CMA8, CPB 1, M MA 7 e M PE8. Em virtude da impossibilidade de 


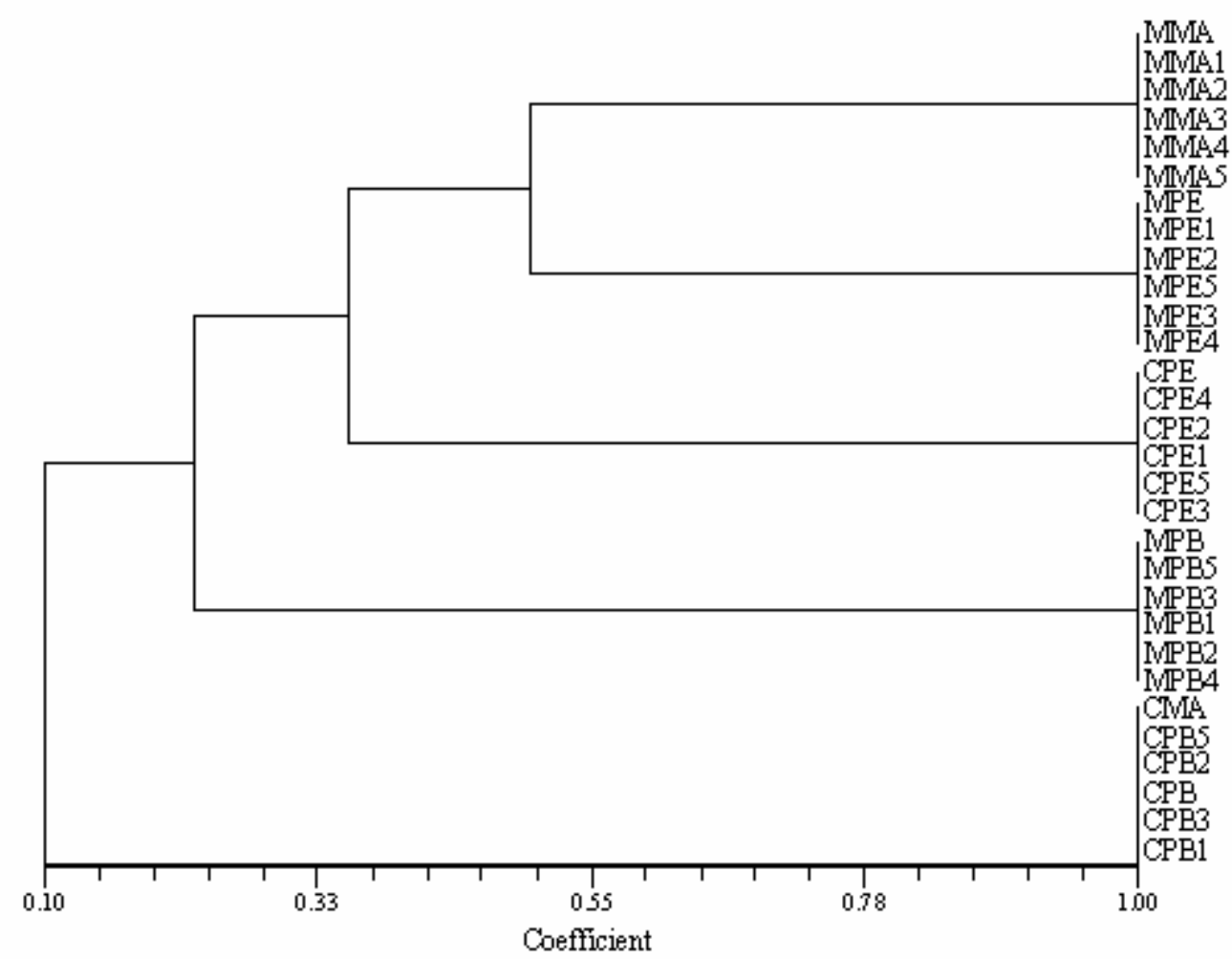

FIGURA 3 - Dendrograma dos isolados (30 monospóricos e 6 multispóricos) de Colletotrichum gloeosporioides obtidos de mangueira e cajueiro baseado na análise isoesterásica, usando o método UPGMA e o coeficiente de Jaccard por meio do programa NTSY S-pc.

análise estatística dos dados, não podem ser asseguradas diferenças entre os isolados. Contudo, em C. graminicola (Ces.) G.W. Wilson, Lima (21) relata que variações em crescimento entre 66,1 e 77,8 $\mathrm{mm}$ foram significativas ao nível de $5 \%$ de probabilidade pelo teste de Tukey. No presente trabal ho foram observadas diferenças no crescimento, entre isolados monospóricos e multispóricos, que variavam de 12 a 15,5 mm. Estes resultados demonstram a possível variação em crescimento micelial entre isolados monospóricos de C. gloeosporioides infectando cajueiro e mangueira. Em relação a aspectos fisiológicos, o trabalho de Madrigal et al. (22), com 0 fungo L. lecanii, evidencia diferenças entre isolados monospóricos e multispóricos.

Os isolados obtidos a partir de M M A (mangueira-M A) foram os que se destacaram com as maiores médias de crescimento micelial, com valores que variaram entre 86,0 a $71,0 \mathrm{~mm}$. 0 isolado que apresentou menor média de crescimento foi o M PB (mangueiraPB) com $60,0 \mathrm{~mm}$ de crescimento aos seis dias, assim como os isolados monospóricos obtidos a partir dele. Há relatos na literatura sobre variação em C. gloeosporioides devido às condições nutricionais e ambientais utilizadas no cultivo do fungo $(20,29$, 33). Tais variações, entre outras, refletem-se no crescimento, produção de conídios, características da colônia e estruturas morfológicas. (Inserir Figura 2)

Com relação aos fatores que influenciam o crescimento micelial e esporulação de espécies do gênero Colletotrichum, F rancisco $\mathrm{N}$ eto et al. (10), trabalhando com isolados de C. gloeosporioides provenientes de $\mathrm{P}$ assiflora, observaram diferenças entre os isolados em relação à capacidade de crescimento e esporulação e constataram também que a luz não influenciou a quantidade de conídios produzidos, porém o meio de cul tura exerceu marcante ef ei to sobre esta característica, variando conforme 0 isolado.
Patogenicidade dos isolados monospóricos e multispóricos

Quanto a patogenicidade, todos os isolados monospóricos e multispóricos foram patogênicos em folhas destacadas de cajueiro e mangueira, induzindo sintomas da doença, caracterizados por manchas escuras e levemente deprimidas e formação de massa conidial sobre as lesões. Os isolados monospóricos obtidos de cajueiro induziram maiores lesões que aqueles provenientes de mangueira. $A$ avaliação patogênica dos isolados, através da variável comprimento de lesão, mostrou diferenças estatísticas significativas dos isolados monospóricos e seus isolados parentais, conforme mostra a Tabela 1.

A variabilidade patogênica é um parâmetro de extrema importância na diferenciação de isolados de C. gl oeosporioides e com isso inúmeros trabalhos têm sido desenvolvidos levando em consideração essa característica $(7,13,17)$. Resultados interessantes em relação a patogenicidade foram também obtidos por Souza \& Sobrinho (31) que demonstraram grande variabilidade morfológica e patogênica de Colletotrichum gloeosporioides oriundos de frutos de mangueiras.

Os isolados de cajueiro CM A e CPE apresentaram menores comprimentos de lesões ( $\mathrm{Pd} " 0,05)$ quando comparados com os isolados monospóricos correspondentes. Os isolados CMA 1 e CPE 4 apresentaram as maiores lesões com 1,02 e 1,45 cm, respectivamente (Tabela 1 ). Não houve diferença estatística significativa entre o isolado CPB e os monospóricos obtidos. D eve ser ressaltada a variação significativa entre isol ados monospóricos dentro de cada multispórico, conforme pode ser observado em relação aos isolados CM A 1, CPE 4 e CPB 4.

Em mangueira, os isolados multispóricos M M A, M PE e M PB induziram maiores tamanhos de lesões e os isolados monospóricos correspondentes apresentaram lesões significativamente menores, ao nível de $5 \%$ de probabilidade. Dentro de cada isolado multispórico de mangueira não foi observada variação significativa 
Tabela 1. M édias do tamanho das lesões formadas em folhas destacadas de mangueira e cajueiro causadas por Colletotrichum gloeosporioides, isolados monospóricos e multispóricos, sete dias após a inoculação.

\begin{tabular}{|c|c|c|c|}
\hline \multicolumn{4}{|c|}{ "Isolado Cajueiro Comprimento $(\mathrm{cm}) *{ }^{1}$ I solados $M$ anguei } \\
\hline CMA 1 & 1,02 a & M M A 1 & $0,57 \mathrm{~b}$ \\
\hline CMA 2 & $0,92 a b$ & M M A 2 & $0,55 \mathrm{~b}$ \\
\hline CMA 3 & $0,85 a b$ & M M A 3 & $0,57 \mathrm{~b}$ \\
\hline CMA 4 & $0,80 \mathrm{bc}$ & M M A 4 & $0,57 \mathrm{~b}$ \\
\hline CMA 5 & $0,82 \mathrm{~b}$ & M M A 5 & $0,60 \mathrm{~b}$ \\
\hline$\underline{\bar{C}} \cdot \bar{v}_{-}^{-}-$ & $-\overline{23}, 4^{-}$ & & $\overline{1} 4,4 \overline{8}$ \\
\hline CPE & $0,50 \mathrm{c}$ & $M P E$ & 1,20 \\
\hline CPE 1 & $0,82 \mathrm{bc}$ & M PE 1 & $0,60 \mathrm{~b}$ \\
\hline CPE 2 & $1,0 \mathrm{~b}$ & M PE 2 & $0,50 \mathrm{~b}$ \\
\hline CPE 3 & $1,17 a b$ & M PE 3 & $0,55 \mathrm{~b}$ \\
\hline CPE 4 & 1,45 a & M PE 4 & $0,57 \mathrm{~b}$ \\
\hline CPE 5 & $1,1 \mathrm{ab}$ & MPE 5 & $0,60 \mathrm{~b}$ \\
\hline$\overline{\mathrm{C}} \cdot \overline{\mathrm{V}}$ & $\overline{15}, \overline{9} 4$ & & $\overline{1} 3,0 \overline{2}$ \\
\hline CPB & $0,95 a b$ & M PB & 1,27 \\
\hline CPB 1 & $0,92 a b$ & M PB 1 & $0,50 \mathrm{~b}$ \\
\hline СРВ 2 & $0,85 \mathrm{~b}$ & M PB 2 & $0,50 \mathrm{~b}$ \\
\hline CРB 3 & $0,85 \mathrm{~b}$ & M PB 3 & $0,55 \mathrm{~b}$ \\
\hline CРB 4 & $1,07 \mathrm{a}$ & M PB 4 & $0,50 \mathrm{~b}$ \\
\hline CРB 5 & $1,0 a b$ & M PB 5 & $0,60 \mathrm{~b}$ \\
\hline $\bar{C} \cdot \bar{V}$ & $\overline{9}, \overline{53}$ & & $13,6 \overline{1}$ \\
\hline
\end{tabular}

* M édia de quatro repetições. Letras minúsculas no sentido vertical não diferem ao nível de $5 \%$ de probabilidade pelo teste de Tukey.

${ }^{1} \mathrm{CMA} / \mathrm{CPE} / \mathrm{CPB} / \mathrm{MMA} / \mathrm{MPE}$ e MPB (isolados multispóricos) e demais isolados monospóricos.

na patogenicidade entre isolados monospóricos. Nesse caso, é importante destacar que os isolados multispóricos foram mais agressivos e, portanto, deveriam ser recomendados em estudos envolvendo a patogenicidade de C. gloeosporioides em mangueira.

Estes resultados diferem daquel es obtidos por Pio-Ribeiro \& Chaves (27) e O liveira et al. (26), que não verificaram diferenças na patogenicidade entre isolados monospóricos e multispóricos de C. lindemuthianum.

Padrões el etroforéticos de isoesterases de isolados monospóricos e multispóricos de Colletotrichum gloeosporioides, em gel de poliacrilamida

D entro do sistema esterásico, o número de bandas variou de uma a três, com predominância de três bandas da esterase para todos os isolados monospóricos e multispóricos obtido de cajueiro e mangueira, com exceção do isolado M PB que apresentou somente uma banda (Est4). A intensidade das bandas variou de maneira independente dos isolados monospóricos e multispóricos e da planta hospedeira (Tabela 2). Todos os isolados, tanto os monospóricos como os multispóricos, apresentaram apenas uma banda monomórfica (Est4) de intensidade mediana e mesma localização no gel $(R f=104,61)$.

0 dendrograma construído por meio do programa NTSY S-pc, utilizando o coeficiente de J accard, reuniu, de acordo com os perfis isoesterásicos, os isolados em dois grupos, sendo um formado pelos monospóricos e multispóricos de mangueira da PB, PE e MA e cajueiro de PE e o segundo por todos os isolados de cajueiro do

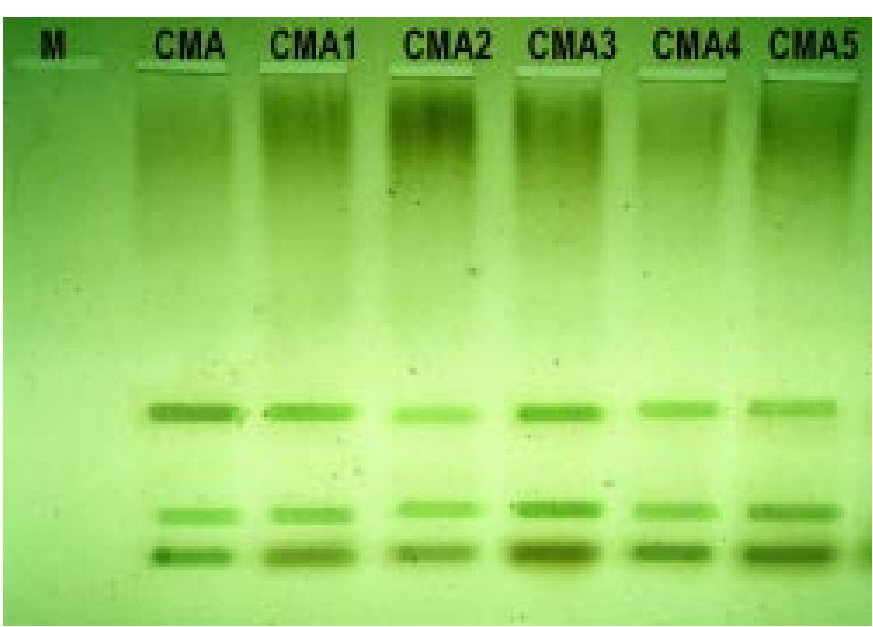

FIGURA 4 - Padrões isoesterásicos apresentados por isolados monospóricos e multispóricos de Colletotrichum gloeosporioides - CMA (isolado de cajueiro proveniente do $M$ aranhão).

* O CM A corresponde ao isolado multispórico e os números de um a cinco aos isolados monospóricos.

M A e PB, os quais apresentaram $100 \%$ de similaridade (F igura 3), mostrando a estreita relação existente entre os isolados no sistema esterásico. Os resultados obtidos evidenciam que não houve polimorfismo quanto a análise isoenzimática entre os isolados monospóricos e multispóricos dos quais foram obtidos (Figura 4).

Com relação às espécies do gênero Colletotrichum, vários trabal hos foram desenvolvidos objetivando comparar padrões protéicos e isoenzimáticos entre: isolados de C. guaranicola (34), C. lindemuthianum (9), C. gloeosporioides $(3,14)$ e C. graminicola $(15,21)$, além de outros. Em todos os casos, os autores observaram variação no número, na intensidade e mobilidade relativa ( $R f$ ) das bandas formadas no gel de poliacrilamida, permitindo visualizar grupos de similaridade entre os isolados de uma mesma espécie.

Segundo B onde et al. (5) a ocorrência de grande polimorfismo para o sistema esterase é esperada devido à participação de vários loci, onde cada um apresenta diferentes tipos de alelos. Bandas produzidas pelo mesmo locus tendem a ocupar a mesma zona no gel. 0 mesmo autor afirma que a freqüência de loci polimórficos indica que as espécies têm considerável variação. De acordo com $M$ ical es et al (25) as isoenzimas são formas moleculares múltiplas de uma mesma enzima e que somente aquelas constituídas de aminoácidos diferentes em carga elétrica ou forma podem ser separadas através da el etroforese, resultando na formação de bandas que representam apenas parte da variabilidade genética de um organismo. Lima (21) afirma que embora cada isolado represente uma população de biótipos, a padronização das condições de cultivos monospóricos, podem reduzir a variação observada em C. graminicola, quanto aos padrões protéicos e isoenzimáticos.

Em função das características morfofisiológicas foi possível detectar diferenças entre os isolados monospóricos e multispóricos de C. gloeosporioides obtidos de cajueiro e mangueira. Os aspectos culturais e crescimento micelial permitiram a distinção entre as culturas monospóricas em relação a alguns isolados. A patogenicidade promoveu uma separação mais efetiva nos isolados de cajuei ro que de mangueira e sugere ser o mel hor parâmetro de escolha de isolados para estudos com C. gloeosporioides. Os padrões eletroforéticos de isoesterases não permitiram evidenciar diferenças entre os isolados monospóricos e multispóricos. Os resultados deste trabalho sugerem que a escolha do tipo de isolado de 
TABELA 2. Número total, intensidade e mobilidade relativa das bandas de esterases apresentadas pelos isolados monospóricos e multispóricos de Colletotrichum gloeosporioides.

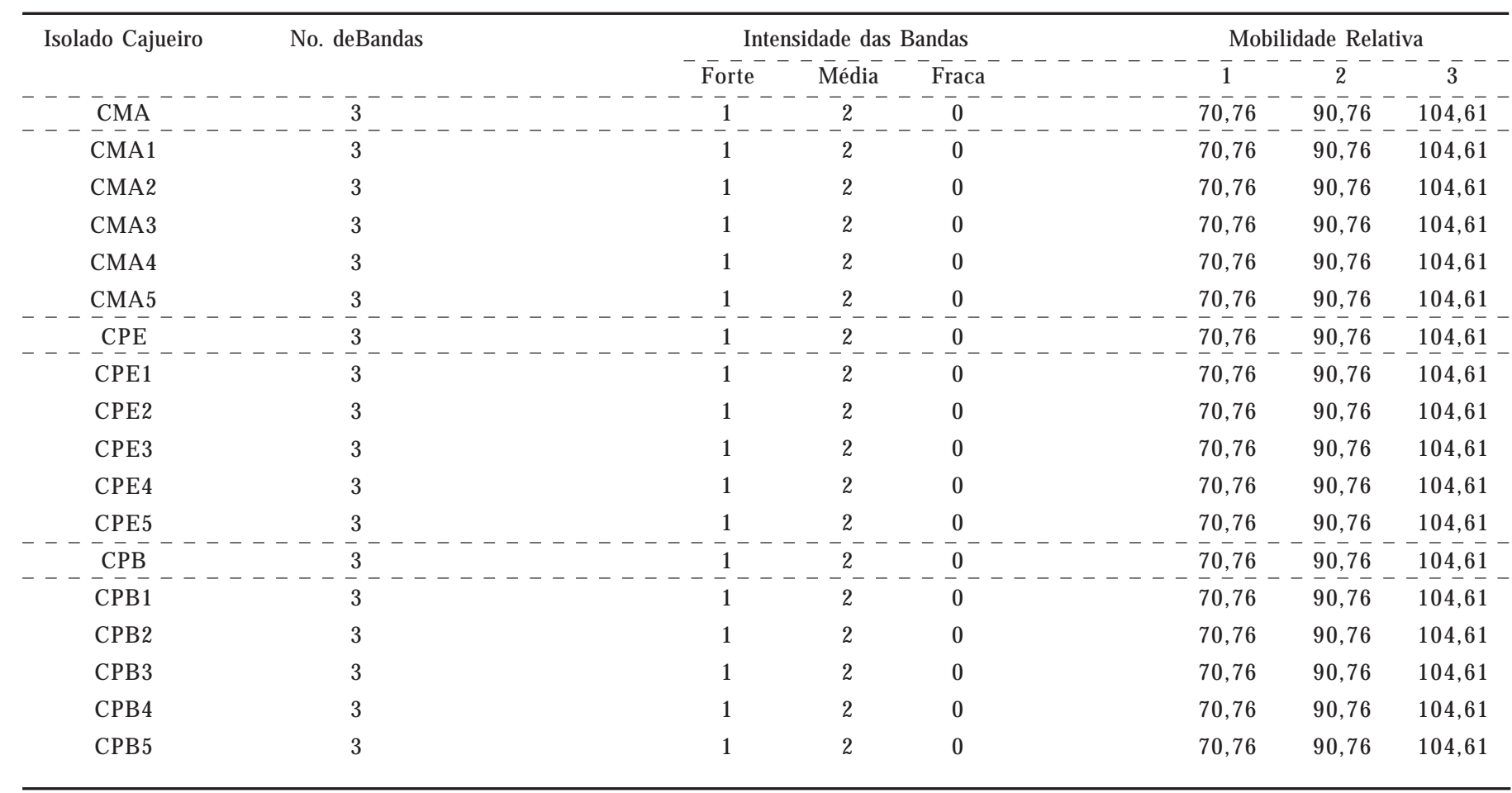

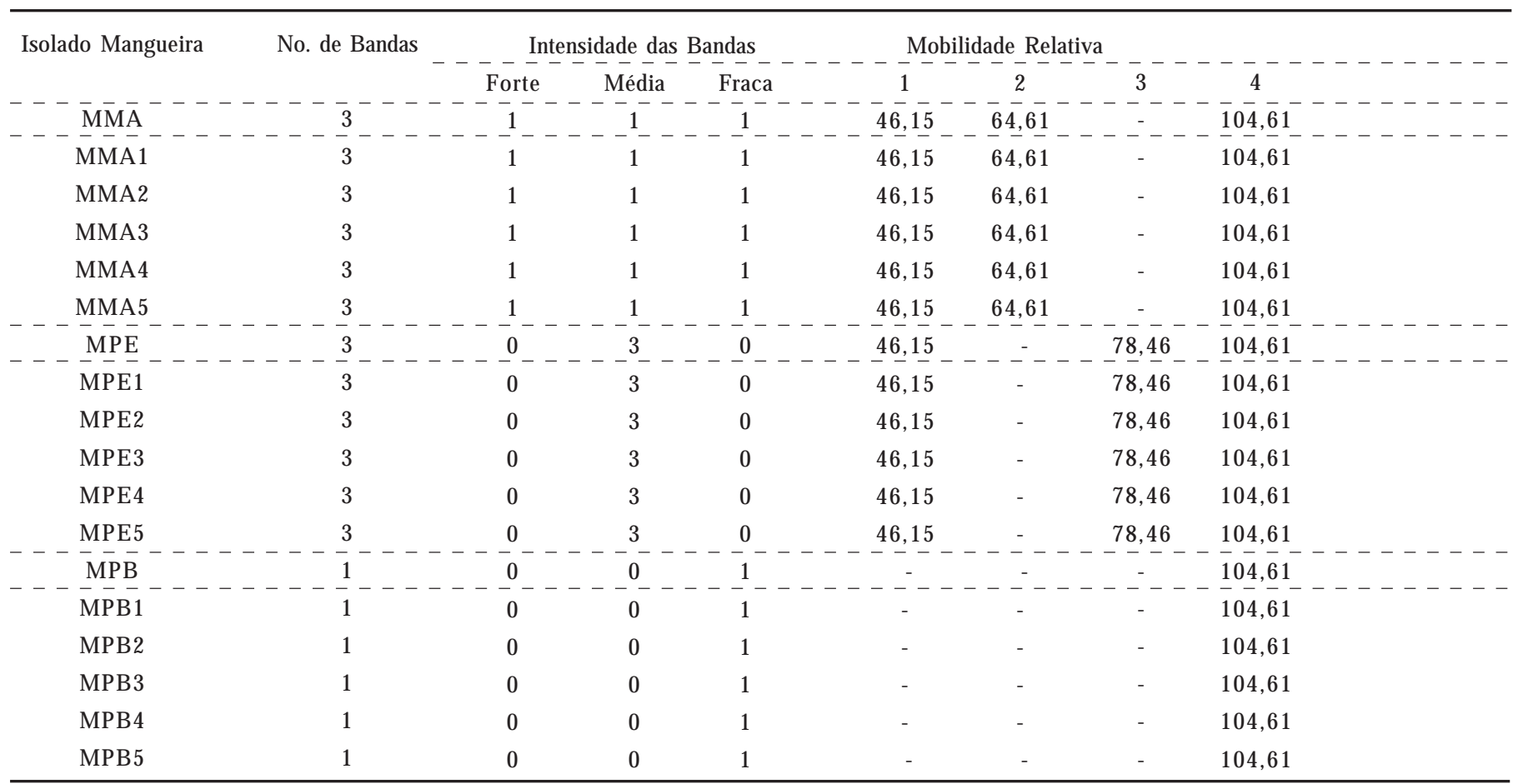

C. gloeosporioides do cajueiro e mangueira e, possivel mente, de outras culturas agrícolas, deve ser feita após análise com base no crescimento micelial e patogenicidade. A ssim sendo, val e ressal tar que o uso bastante difundido das culturas monospóricas em C. gloeosporioides, sem prévia análise, pode garantir uniformidade genética, mas não representatividade do isolado na população do fungo.

\section{REFERÊNCIASBIBLIOGRÁFICAS}

1. A fanador-K afuri, L; M inz, D.; M aymon, M .; Freeman, S. Characterization of Colletotrichum isolates from tamarillo, passiflora, and mango in Colombia and identification of a unique species from the genus. Phytopathology, St. Paul, v.93, p.579-587, 2003.

2. Alfenas, C. A.; Peters, I.; Brune, W.; Passador, G. C. Eletroforese de proteínas e isoenzimas para identificação de espécies de fungos e essências florestais. Viçosa: UFV, 1991. 242p.

3. Assis, T. C. Variabilidade de Colletotrichum gloeosporioides, agente causal da antracnose da mangueira, quanto utili- 
zação de carboidratos, patogenicidade, produção de enzimas e analise RAPD. 2001. 67f. Dissertação (M estrado em Fitossanidade) - Universidade Federal Rural de Pernambuco, Recife.

4. Bach, E.E. Utilização de eletroforese no estudo de alterações enzimáticas na interação planta-patógeno. In: Encontro sobre A plicações de Eletroforese na A gropecuária, 1., 1989, Nova O dessa. A nais... Nova Odessa: Instituto de Zootecnia, 1989. p.1-4.

5. Bonde, M.R.; Micales, J.A.; Peterson, G.L. The use of isozyme analyses for identification of plant-pathogenic fungi. Plant Disease, St. Paul, v.77, p.961-968, 1993.

6. Denoyes, B.; Baudry, A. Species identification and pathogenicity study of French Colletotrichum strains isolated from strawberry using morphological and cultural characteristics. Phytopathology, St. Paul, v. 85, p.53-157, 1995.

7. Denoyes, B.; Guerin, G.; Delye, C.; Smith, B.; M inz, D.; M aymon, M.; Freeman, S. Genetic diversity and pathogenic variability among isolates of Colletotrichum from strawberry. Phytopathology, St. Paul, v. 93, p.219-228, 2003.

8. Ferraz, J.F.P. Morfologia, comportamento cultural e patogenicidade de espécies de Colletotrichum e Gloeosporium. Agronomia Lusitana, Oeiras, v.38, p.163-179, 1977.

9. Figueiredo, G.; Alfenas, A. C.; Brommonschenkel, S. H.; Faria, J. C. Variabilidade isoenzimática de isolados de Colletotrichum lindemuthianum com diferentes níveis de virulências. Arquivos de Biologia e Tecnologia, Curitiba, v.36, p.793-808, 1993.

10. Francisco Neto, E.; Nakamura, K.; Oliveira, J. C. Influência de alguns fatores na germinação de conídios, no crescimento micelial e na esporulação de alguns isolados de Colletotrichum gloeosporioides, obtidos de Passiflora. Summa Phytopathologica, Jaguariúna, v.20, p.96-100, 1994.

11. Freeman, S.; Katan, T.; Shabi, E. Characterization of Colletotrichum species responsible for anthracnose diseases of various fruits. Plant Disease, St Paul, v.82, n.6, p.596-605, 1998.

12. Freeman, S. Genetic diversity and host specificity of Colletotrichum species on various fruits. In: Prusky, D.; Freeman, S.; Dickman, M.B. (Ed.). Colletotrichum: Host specificity, Pathology and Host-pathogen interaction. St. Paul: A PS Press. 2000. p.131-143.

13. Freeman, S.; Shalev, Z.; Katan, T. Survival in soil of Colletotrichum acutatum and $C$. gloeosporioides pathogenic on strawberry. Plant Disease, St. Paul, v.66, p.965-970, 2002.

14. Furtado, E.L.; Bach, E.E.; Kimati, H.; Menten, J.O.M.; Silveira, A.P. Caracterização morfológica, patogênica, e isoenzimática de isolados de Colletotrichum gloeosporioides de seringueira. Summa Phytopathologica, Jaguariúna, v.25, p.222-228, 1999.

15. Horvath, B.J.; Vargas Jr. J.M. Genetic variation among Colletotrichum graminicola isolates from four hosts using isozyme analysis, Plant Disease, St. Paul, v.88, p.402-406, 2004

16. Kimati, H.; A morim, L.; Rezende, J.A.M.; Bergamin Filho, A.; Camargo, L.E.A. Manual de fitopatologia: doenças de plantas cultivadas. 4. ed. São Paulo: Ceres, 2005. v.2, p.607-626.

17. Katan, T. Vegetative compatibility in Colletotrichum. In: Prusky, D.; Freeman, S.; Dickman, M. (Eds.) Colletotrichum: Host Specificity, Pathology and Host-Pathogen Interaction, St. Paul: APS Press. 2000. p.145-179.

18. K aufmann, P.J.; Weidemann, G.J. Isoezyme analysis of Colletotrichum gloeosporioides from five host genera. Plant Disease, St. Paul, v.80, p.1289-1293, 1996.

19. Johnston, P.R.; Jones, D. Relationships among Colletotrichum isolates from fruit-rots assessed using rDNA sequences. Mycological, N ew York, v.89, p.420-430, 1997

20. Latinovié, J.; Vueinié, Z. Cultural characteristics, pathogenicity, and host range de Colletotrichum gloeosporioides isolated from olive plants in M ontenegro. Acta Hortsciense, Alexandria, v.586, p.753-755, 2002.

21. Lima, M. L. F. Caracterização patogênica, fisiológica e enzimática de isolados de Colletotrichum graminicola,(Ces.) G.W. Wilson agente causal da antracnose em milho, Zea mays L 2000. 70f. Dissertação (M estrado em Fitossanidade) Universidade Federal Rural de Pernambuco, Recife.

22. M adrigal-Cortez, H.; A latorre-Rosas, R.; M ora-A guilera, G.; Bravo-M ojica, H.; Ortiz-Garcia, C.F.; A ceves-Navarro, L.A. Characterization of multisporic and monosporic isolates of LecaniciIlium (=Verticillium) lecanii for the management of Toxoptera aurantii in cocoa. Bioncontrol, Netherlands, v.48, p.321-334, 2003.

23. Menezes, M. A spectos biológicos e taxonômicos de espécies do gênero Colletotrichum. Fitopatologia Brasileira, Fortaleza, v.27, Supl., p.523-524, 2002.

24. Menezes, $M$. Doenças do cajueiro. In: K imati, H., A morim, L., Rezende, J.A.M., Bergamin Filho, A.\& Camargo, L.E.A. (Ed.). $M$ anual de fitopatologia: doenças de plantas cultivadas, 4. ed. São Paulo: Ceres, 2005. v.2, p.181-184.

25. Micales, J.A.; Alfenas, A.C.; Bonde, M.R. Isoenzimas na taxonomia e na genética de fungos. In: Alfenas, A.C. (Ed.). Eletroforese de isoenzimas e proteínas afins. Viçosa: Universidade Federal de Viçosa, 1998, cap. 10, p.477-512.

26. Oliveira, E.A.; A ntunes, I.F.; Costa, J.G. C. Raças fisiológicas de Colletotrichum lindemuthianum identificadas no Rio Grande do Sul e em Santa Catarina de 1968 a 1972. Pelotas: IPEAS, 1973. 5 p. (Comunicado Técnico).

27. Pio-Ribeiro, G.; Chaves, G. M. Estudo sobre variabilidade de isolamentos e culturas monospóricas de Colletotrichum lindemuthianum (Sacc. \& Magn.) Scrib. Experientiae, Viçosa, v.19, p. $59-71,1975$.

28. Ribeiro, I.J.A. Doenças da mangueira. In: Kimati, H., A morim, L., Rezende, J.A.M., Bergamin Filho, A.\& Camargo, L.E.A. (Ed.). $M$ anual de fitopatologia: doenças de plantas cultivadas, 4. ed. São Paulo: Ceres, 2005. v.2, p.457-465.

29. Screennivasaprasad, S.; Talhinhas, P.; Genotypic and phenotypic diversity in Colletotrichum acutatum, a cosmopolitan pathogen causing anthracnose on a wide range of hosts. Molecular Plant Pathology, London, v.6, p.361-378, 2005.

30. Serra, I.M.R.S.; Silva, G.S. Caracterização morfofisiológica de isolados de Colletotrichum gloeosporioides agentes de antracnose em frutíferas no M aranhão. Summa Phytopathologica, B otucatu, v.30, p. 475-480, 2004.

31. Souza, C. L. C.; Sobrinho, C. A . Avaliação da variabilidade morfológica e patogênica do agente causal da antracnose na mangueira. Fitopatologia Brasileira, Fortaleza, v.33, p.426, 2000. (Resumo).

32. Talhinhas, P.; Screennivasaprasad, S.; Neves-M artins, J.; Oliveira, H. Molecular and phenotypic analyses reveal the association of diverse Colletotrichum acutatum groups and a low level of $C$. gloeosporioides with olive anthracnose. Applied Environmental Microbiology, Washington, v.71, p.2987-2998, 2005.

33. Tandon, R.N.; Chandra, S. The nutrition of Colletotrichum gloeosporioides Penz. Mycopathologia et Mycologia Applicata, Denhaag, v.18, p.213-224, 1962.

34. Véras, S.M.; Gasparotto, L.; M enezes, M. Avaliação isoenzimática de Colletotrichum guaranicola. Arquivos de Biologia e Tecnologia, Curitiba, v.40, p.548-553, 1997

35. Xiao, C.L.; M ackenzie, S.J.; Legard, D.E. Genetic and pathogenic analyses of Colletotrichum gloeosporioides isolates from strawberry and noncultivated hosts. Phytopathology, St. Paul, v.94, p. $446-453,2004$. 